\title{
Dielectrophoresis Structurization of PZT/PDMS Micro-Composite for Elastronic Function: Towards Dielectric and Piezoelectric Enhancement
}

\author{
Giulia D’Ambrogio, Omar Zahhaf, Minh-Quyen Le $\mathbb{C}^{\mathbb{B}}$, Jean-Fabien Capsal $\mathbb{( 1 )}$ and Pierre-Jean Cottinet *
}

check for updates

Citation: D'Ambrogio, G.; Zahhaf, O.; Le, M.-Q.; Capsal, J.-F.; Cottinet, P.-J. Dielectrophoresis Structurization of PZT/PDMS Micro-Composite for Elastronic Function: Towards Dielectric and Piezoelectric Enhancement. Materials 2021, 14, 4071 https://doi.org/10.3390/ma14154071

Academic Editors: Lorena Pardo, Sebastiano Garroni and Amador M. González

Received: 24 June 2021

Accepted: 19 July 2021

Published: 21 July 2021

Publisher's Note: MDPI stays neutral with regard to jurisdictional claims in published maps and institutional affiliations.

Copyright: (c) 2021 by the authors. Licensee MDPI, Basel, Switzerland. This article is an open access article distributed under the terms and conditions of the Creative Commons Attribution (CC BY) license (https:/ / creativecommons.org/licenses/by/ $4.0 /)$.
Univ. Lyon, INSA-Lyon, LGEF, EA682, Electrical Department, Ladoua Campus, F-69621 Villeurbanne, France; giulia.dambrogio@insa-lyon.fr (G.D.); omar.zahhaf@insa-lyon.fr (O.Z.); minh-quyen.le@insa-lyon.fr (M.-Q.L.); jean-fabien.capsal@insa-lyon.fr (J.-F.C.)

* Correspondence: pierre-jean.cottinet@insa-lyon.fr

\begin{abstract}
Piezoelectric materials have been used for decades in the field of sensors as transducers and energy harvesters. Among these, piezoelectric composites are emerging being extremely advantageous in terms of production, costs, and versatility. However, the piezoelectric performances of a composite with randomly dispersed filler are not comparable with bulk ferroelectric ceramics and electroactive polymers. In order to achieve highly performing and low-cost materials, this work aims to develop flexible composites made of Lead zirconate titanate (PZT) filler in Polydimethylsiloxane (PDMS) matrix, with a specific internal structure called quasi-1-3 connectivity. Such a structure, comprising particles arranged in columns along a preferred direction, is performed through dielectrophoresis by applying an alternating electric field on the composite before and during the polymerization. The developed flexible material could be introduced into complex structures in various application fields, as sensors for structural monitoring.
\end{abstract}

Keywords: ferroelectric composites; piezoelectric sensor; health monitoring; 1-3 connectivity; dielectrophoresis; smart materials

\section{Introduction}

Piezoelectric composites made of ferroelectric ceramic fillers embedded in polymeric matrix are commonly used as transducers, actuators, and sensors. Thanks to the combination of the constituent phases, piezocomposites exhibit good mechanical properties and piezoelectric activity [1-6]. By properly combining particles and polymer matrix, it is possible to tailor the features of the final material and thus to develop sensors for specific application [7-9]. By choosing a flexible matrix, piezoelectric composites can be less fragile than bulk ceramics, such as bulk lead zirconate titanate (PZT) and barium titanate $\left(\mathrm{BaTiO}_{3}\right)$ [10]. Moreover, the appropriate selection of a ferroelectric filler results in materials operating at high temperatures, and therefore more advantageous than classical electroactive polymers like polyvinylidene difluoride (PVDF), P(VDF-TrFE) copolymer, and P(VDF-TrFE-CTFE) terpolymer [11-17]. Additional advantages are the low cost, ease of manufacture and reduced polarization electric field compared to common electroactive fluoropolymers [18]. In view of all these aspects, piezoelectric composites are thriving as transducer in different fields such as aerospace, automotive, nuclear, and medical. In the industrial sector they play a fundamental role in the structural health monitoring. This process consists in the examination of the safety and durability of structures, and in the detection of any damage or defect that could lead to catastrophic failures. Among all the non-destructive tests, the use of sensors based on piezoelectric composites is an interesting solution. Their main advantage would be that, placed permanently on a structure, they could allow an online monitoring during the service life [19-21]. Piezoelectric composite sensors are also widely used in the medical fields for high frequency ultrasound imaging, in 
infusion, insulin pumps, respiratory monitoring, in blood pressure monitoring equipment and surgical fluid management systems [22-28].

The arrangement of the phases, named as connectivity, determines the performance of these composites. Different possible arrangements of the phases can be exploited to tailor the piezoelectric properties of the composites [25,29]. It is thus possible to design a proper structure within the material to enhance the efficiency of the sensor $[1,30,31]$. Several studies demonstrate that a columnar arrangement of the fillers within the matrix, named 1-3 connectivity, improves the piezoelectric response along the alignment direction, with respect to a composite with filler randomly dispersed, named 0-3 connectivity [32-35]. 1-3 connectivity can be designed through several techniques such as rod placement, dicefill, ultrasonic cutting, laser machining, co-extrusion, tape lamination, and fiber insertion method [3]. Among the various existing methods, electric field structuration via dielectrophoresis emerges as a promising process: an electric field is applied to the sample before (at ambient temperature) and during the curing process (at high temperatures) in order to drive the particles into a columnar structure [25,34,36-38]. The high temperature applied in the second stage of the process fixes the build-up design. Usually, the electric field distribution in a composite is non-homogeneous due to the discrepancy in permittivity between the matrix and the particles. This leads to a generation of dipoles in the ceramic particles, which, as a consequence, attract and repulse each other's by electrostatic force, depending on their reciprocal position. When the matrix is cured under the electric field, the columns maintain their position to form a chain-like structure. This method is particularly convenient because of its easy processability, i.e., the possibility to be integrated in additive manufacturing based 3D printing technology [21,39,40]. In 1-3 connectivity, the particles redistribute themselves along columns, creating anisotropy in the material. The particles within the chain are tightly packed and experience strong interactions in the aligned direction [41]. A further benefit of the structuration is a reduction of the poling electric field required to trigger the piezoelectric activity. The distribution of the ceramic phase in parallel columns provokes a more effective distribution of the electric field within the composite, thus a better piezoelectric coupling. During the poling, the matrix shields less the electric field in an aligned 1-3 matrix, as opposed to a random 0-3 counterpart, where the shielding does not allow functional poling unless high electric fields are applied [42].

In this work, we demonstrate strong benefit of material structuration via dielectrophoretic technique. A comparison of both $0-3$ and 1-3 connectivity is performed via Scanning electron microscopy (SEM) analysis, together with dielectric and piezoelectric characterizations. Experimental data are correlated to analytical models. In addition, thermal stability and high temperature $\mathrm{X}$-ray diffraction analyses are investigated, confirming good piezoelectric response even at $200^{\circ} \mathrm{C}$. Dielectrophoresis reveals to be frequency dependent, which might affect the alignment's degree of the piezoelectric phase. This analysis allowed to select the best parameters for achieving 1-3 PZT/PDMS composite.

\section{Materials and Methods}

\subsection{Sample Preparation}

Lead zirconate titanate is an inorganic compound with the following chemical formula $\mathrm{Pb}\left[\mathrm{Zr}_{\mathrm{x}} \mathrm{Ti}_{1-\mathrm{x}}\right] \mathrm{O}_{3}(0 \leq \mathrm{x} \leq 1)$. In literature it is usually simplified as PZT, which includes all the possible types of this compound. In this research, a commercial PZT 52/48 was used, with an average size of $3.8 \mu \mathrm{m}$, and a mass density $(\rho)$ of $7600 \mathrm{~g} \mathrm{~cm}^{-3}$. The polymer used was linear vinyl terminated poly(dimethylsiloxane) Sylgard 184 elastomer, purchased at Dow Corning ${ }^{\circledR}$. It was crosslinked with the curing agent by a ratio of 10 (base): 1 (curing agent). Powder and Sylgard base were weighted and mixed in a ultrasonication mixer for 10 min under I Type Cabinet B -ADS air Clean. The cross-linker was added in the mentioned ratio and mechanically mixed for $1 \mathrm{~min}$. The mixture was dried under vacuum at $23{ }^{\circ} \mathrm{C}$ for $30 \mathrm{~min}$ in Memmert Vacuum oven. The blend was then poured into a mold consisting of a mylar spacer $250 \mu \mathrm{m}$-thick and a $3 \times 3 \mathrm{~cm}^{2}$ surface of cut-out positioned between an upper aluminum plate (placed under a $500 \mathrm{~g}$ mass), and a bottom aluminum 
plate. Aluminum plates played a role of electrodes, from which a structuring field created $1-3$ connectivity (Figure 1a). The mold was placed in an oven. For 0-3 composite, the oven was immediately switched on at $150^{\circ} \mathrm{C}$ during $1 \mathrm{~h}$. For 1-3 composites, the aluminum plates were connected to a voltage amplifier coupled with a sinusoidal wave generator. An

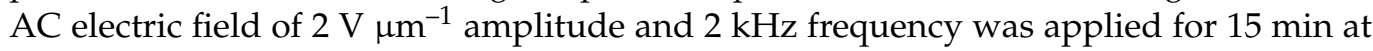
room temperature. Later, the oven was started at $150{ }^{\circ} \mathrm{C}$ and the blend was left cooking under external electric field for $1 \mathrm{~h}$. The volume fraction prepared were $3.2 \% \mathrm{vol}, 12 \% \mathrm{vol}$ and $24 \%$ vol. Before performing the polarization, all the samples were sputtered with gold, to produce circular electrodes of $0.8 \mathrm{~mm}$ diameter and $25 \mathrm{~nm}$ thick on the top and bottom surfaces. The samples were then submerged in a silicone oil bath at $100{ }^{\circ} \mathrm{C}$ and poled for $30 \mathrm{~min}$ under a DC electric field of $20 \mathrm{~V} \mathrm{\mu m}^{-1}$, which was found to be close to the coercive field of $1-3$ composite at $24 \%$ vol (Figure $1 \mathrm{~b}$ ). The choice of a DC poling procedure instead of a bipolar polarization is related to the properties of the composite, which usually consists of two components: polymer matrix and ceramic filler. Considering the typical hysteresis curve of Current vs. Electric field of an alternating bipolar poling, the capacitive behavior of the polymer would mask the ferroelectric behavior of the filler. As a matter of fact, the ferroelectric current is quite small with respect to the capacitive component of the polymer [18,43-45].

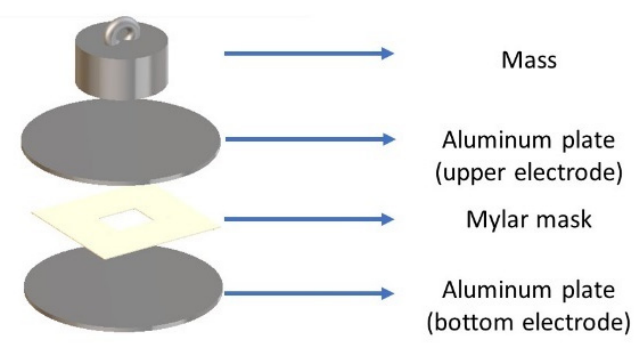

(a)

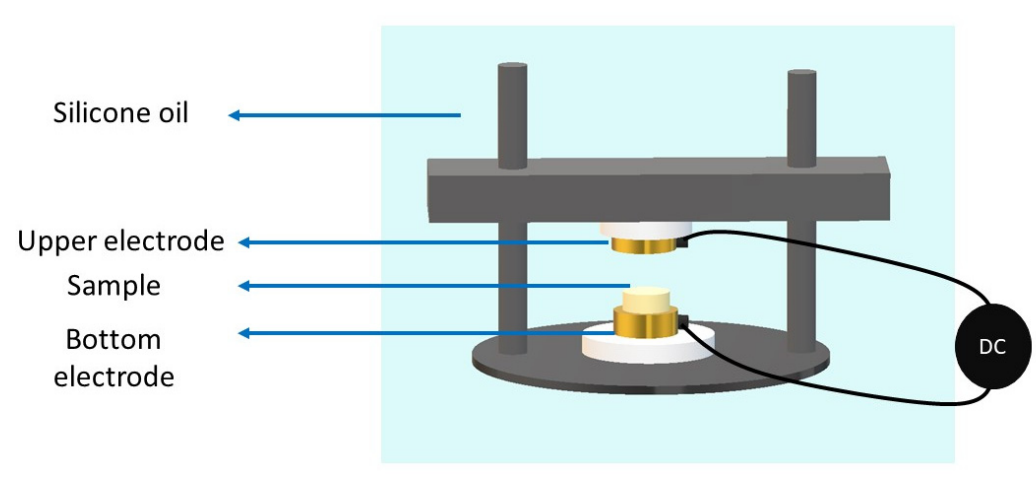

(b)

Figure 1. (a) Set up developed to produce the composites. (b) Poling set up.

\subsection{Scanning Electron Microscopy}

Scanning electron microscopy (SEM) was performed via Hitachi FlexSEM $1000 I$ I model (Hitachi High-Tech Corporation, Tokyo, Japan), with the aim of analyzing the morphology of PZT particles and visualizing the phases configuration in $0-3$ and 1-3 connectivity at $1 \%$ vol. Image-J software (Version 1.44, National Institutes of Health, Bethesda, MD, USA) was then employed to determine the size distribution and the real shape of the particles.

\subsection{Dielectric Spectroscopy}

Dielectric test was performed through Solarton spectrometer 1296A Dielectric Interface System (1255, Oak Ridge, TN, USA) to obtain the dielectric permittivity of PZT/PDMS 0-3 
and 1-3 composites. The real part of the dielectric permittivity at $1 \mathrm{kHz}$ was recorded as a function of the volume content.

\subsection{Piezoelectric Sensitivity}

Piezoelectric charge coefficient, $\mathrm{d}_{33}(\mathrm{pC} / \mathrm{N})$, was measured with APC $\mathrm{d}_{33} \mathrm{~m}$. The piezoelectric sensitivity was measured relied on the Berlincourt method: a sample was clamped between two probes and subjected to a force at $110 \mathrm{~Hz}$ and a variation of $0.25 \mathrm{~N}$. Through the upper probe, a static preload force was applied.

\subsection{Thermal Analysis and X-ray Diffraction}

With the aim of understanding the piezoelectric activity of the composites at high temperature, a thermal analysis was performed. The samples were annealed at different temperatures $\left(50{ }^{\circ} \mathrm{C}, 100{ }^{\circ} \mathrm{C}, 150{ }^{\circ} \mathrm{C}\right.$, and $200{ }^{\circ} \mathrm{C}$ ) for $10 \mathrm{~min}$ after poling (following the procedure reported previously in Section 2.1). Subsequently, after each annealing step, the piezoelectric charge coefficient, $\mathrm{d}_{33}$, was measured. This analysis was coupled with an X-ray diffraction study, performed at different temperatures $\left(25^{\circ} \mathrm{C}, 150{ }^{\circ} \mathrm{C}\right.$, and $\left.200{ }^{\circ} \mathrm{C}\right)$, in order to understand the relationship between the piezoelectric activity and the crystalline phases in the ceramic filler. The XRD study was carried out using Philips X'Pert MPD diffractometer (Philips, Amsterdam, Netherlands) with carbon filtered CuKa (1.5406 ̊) source.

\subsection{In-Situ Microscopy}

In situ microscopy was the final step required to investigate the process of structuring. Among all the parameters that affect dielectrophoretic technique, this work focused on the frequency dependency. A blend of particles and polymer with a volume content of $1 \%$ vol was prepared, without launching the polymerization stages. A portion of the blend was collected with a dropper and placed on a microscopy glass, between two copper electrodes previously installed. The electrodes were connected to a voltage amplifier coupled with a wave generator. A flashlight was positioned above the glass, while a USB-microscope was placed below it and connected to a computer. The observations lasted $15 \mathrm{~min}$ at a fixed electric field amplitude of $2 \mathrm{~V} \mathrm{~mm}^{-1}$, while different frequencies of $2 \mathrm{kHz}$ and $2 \mathrm{~Hz}$ were applied. The experimental set up is illustrated in Figure 2. Frames at 0, 5, 10, and $15 \mathrm{~min}$ were taken from the videos for the two different observations, and the pictures were qualitatively compared.

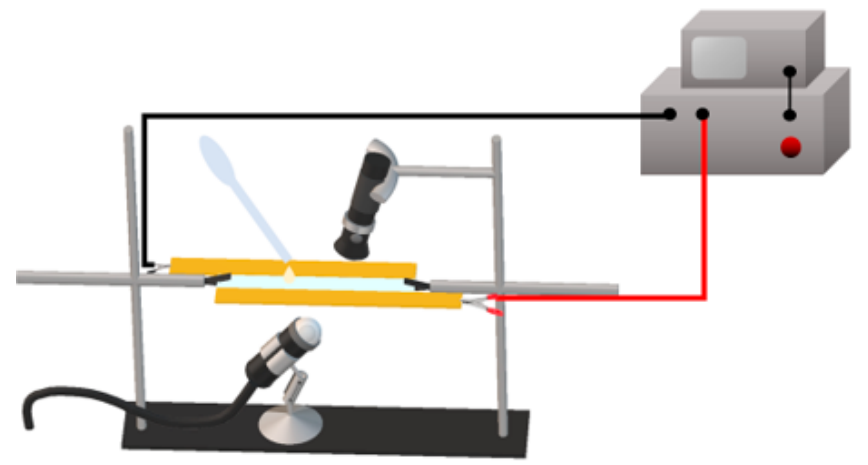

Sinusoidal Wave Generator

Voltage Amplifier

Figure 2. In-situ microscopy set up.

\section{Results and Discussion}

\subsection{SEM Observation}

The particles size was $3.8 \mu \mathrm{m}$, with a standard deviation of 1.6. Figure 3 is a picture of the particles taken via SEM in Back scattered electron mode (BSE). SEM pictures of the cross section of $0-3$ and $1-3$ composite with a volumetric content of $1 \%$ vol are illustrated 
in Figure 4a,b. The analysis highlights the different distribution of the fillers in the two connectivity, being a clear proof of the effect of dielectrophoretic alignment.

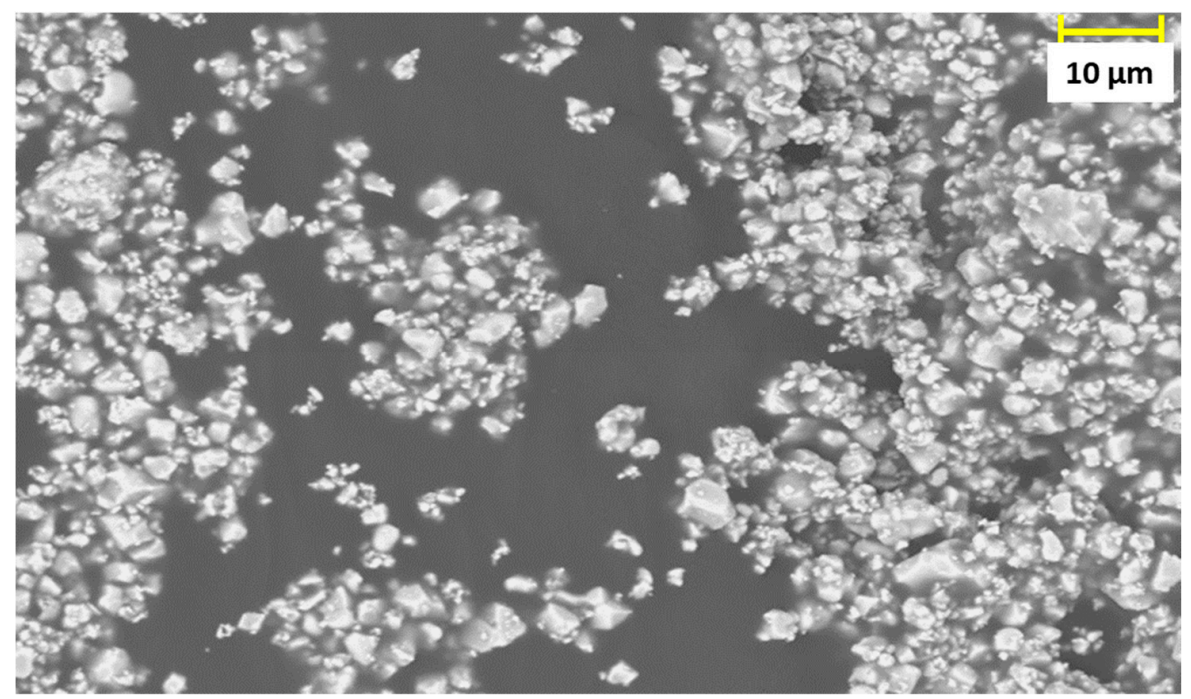

Figure 3. SEM picture, taken in back scattered electrons mode (BSE) of PZT fillers.

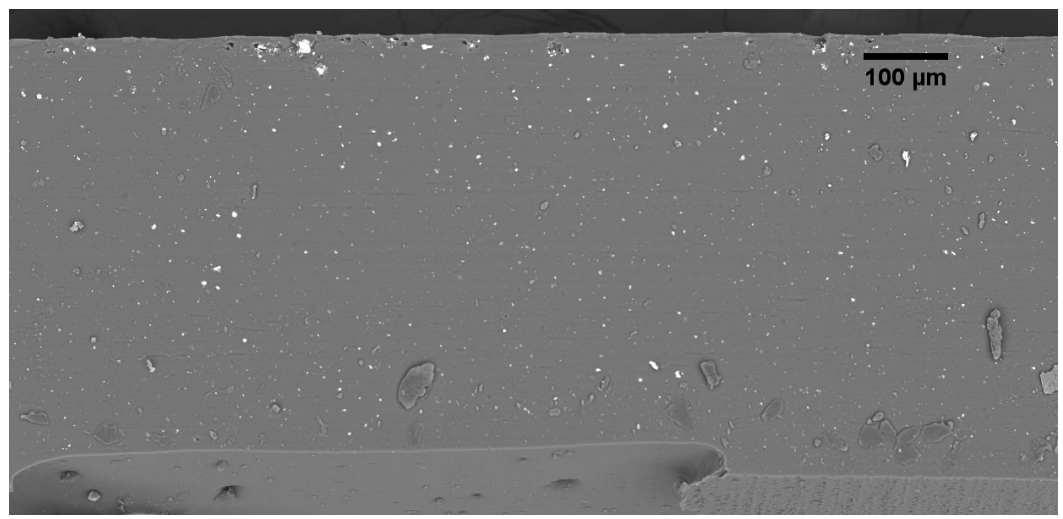

(a)

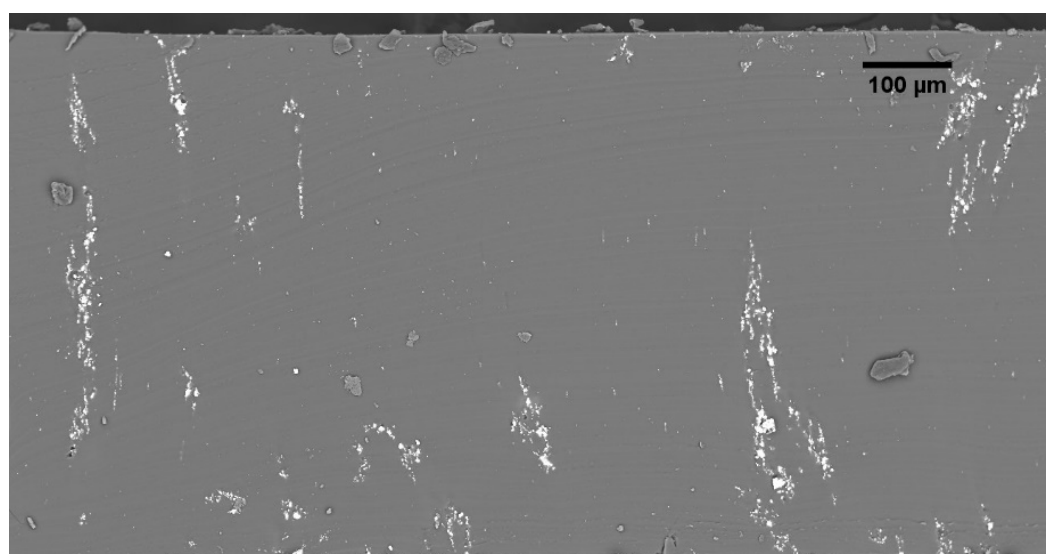

(b)

Figure 4. SEM images of the cross section of PZT/PDMS composite with $1 \%$ vol of filler: (a) 0 3 connectivity; (b) 1-3 connectivity. 


\subsection{Dielectric and Piezoelectric Behavior}

As expected, the dielectric properties of 1-3 composites were higher at each volume content, as depicted in Figure 5a. The rearrangement of the fillers within the matrix affects the electric field distribution and this leads to an increase of permittivity. The enhancement of permittivity is a proof that dielectrophoresis induces change of composite properties by creating anisotropy. To summarize, it is quite clear that the distribution of the phases has an important effect on the measured dielectric properties. As a result of field-structuring, relative permittivity is increased along the field direction, whatever the volume content. Experimental results were compared to theoretical data established through the models developed by Yamada et al. (for 0-3 connectivity) and Bowen et al. (for 1-3 connectivity) $[8,42,46]$. Yamada's model describes $0-3$ composites as made by ellipsoidal particles homogeneously dispersed in the matrix and the composite is considered to be mechanical and electrical loss free (Equation (1)). Bowen's model describes the system as made of perfect cubic particles disposed in aligned chains (Equation (2)). According to the model, the cubic fillers are capacitors in series with the matrix within the chains. These chains are connected in parallel to the matrix region outside of the chains, which is depleted of particles. As shown in Figure 5a, the results follow the trend presumed by the models in both configurations.

The following equation describes Yamada's model for dielectric properties of 0-3 connectivity composites:

$$
\varepsilon_{0-3}=\varepsilon_{\mathrm{p}}\left(1+\frac{\mathrm{n} \varphi\left(\varepsilon_{\mathrm{f}}-\varepsilon_{\mathrm{p}}\right)}{\mathrm{n} \varepsilon_{\mathrm{p}}+\left(\varepsilon_{\mathrm{f}}-\varepsilon_{\mathrm{p}}\right)(1-\varphi)}\right)
$$

where $\varepsilon_{\mathrm{p}}$ and $\varepsilon_{\mathrm{f}}$ are the real part of the permittivity of the polymer and of the filler respectively; $\varphi$ is the filler volume content, and $\mathrm{n}$ is the inverse of the depolarization factor dependent on the geometry of the particles.

Bowen's model is given by:

$$
\varepsilon_{1-3}=\varphi\left(\frac{\mathrm{r} \varepsilon_{\mathrm{f}} \varepsilon_{\mathrm{p}}}{\varepsilon_{\mathrm{f}}+\varepsilon_{\mathrm{p}} \mathrm{r}}\right)+(1-\varphi) \varepsilon_{\mathrm{p}}
$$

where $r$ indicates the ration between the dimension of each filler and the interparticle distance within a chain.

Figure $5 b$ depicts the piezoelectric charge coefficient $\left(d_{33}\right)$ at different filler volume fractions. As expected, the structured samples exhibit higher $\mathrm{d}_{33}$, regardless of the volume fraction content. The 1-3 connectivity induces anisotropy leading to enhanced piezoelectric properties along the column direction. Ceramic particles concentration is enhanced along the thickness direction, while the other directions are depleted of particles [33,42]. Moreover, the distribution of the phases determines the local field intensity, and therefore provokes a certain polarization. In structured composites, for instance, the distribution of the electric field reveals to be more favorable and as a result it allows greater polarization $[25,43]$. In a composite, the electric field usually concentrate in the polymer matrix rather than in the filler, due to the lower dielectric properties of the polymer. However, in 1-3 configuration, the electric field focuses mostly on the polymer gaps between the particles, making polarization of ferroelectric particles significantly enhanced. In 0-3 connectivity, using the same electric field as in the case of 1-3 counterpart is not sufficient enough to reach the most optimized polarization $[25,43]$.

In this work, the experimental results were compared with the analytical models: Yamada's model for $\mathrm{d}_{33}$ in 0-3 connectivity (Equation (3)), and Van den Ende's model for $\mathrm{d}_{33}$ in 1-3 connectivity (Equation (4)) [8,33].

$$
\mathrm{d}_{330-3}=\varphi \alpha \frac{\mathrm{n} \varepsilon_{0-3}}{\mathrm{n} \varepsilon_{0-3}+\left(\varepsilon_{\mathrm{f}}-\varepsilon_{0-3}\right)} \mathrm{d}_{33 \mathrm{f}}
$$




$$
\mathrm{d}_{331-3}=\frac{(1+\mathrm{r})^{2} * \varepsilon_{\mathrm{p}} * \varphi * \mathrm{Y}_{33 \mathrm{f}} * \mathrm{~d}_{33 \mathrm{f}}}{\left(\varepsilon_{\mathrm{f}}+\mathrm{r} \varepsilon_{\mathrm{p}}\right) *\left[(1+\mathrm{r} \varphi) * \mathrm{Y}_{33 \mathrm{f}}+(1-\varphi) * \mathrm{r} \mathrm{Y}_{\mathrm{p}}\right]}
$$

where $\alpha$ is the poling ration of the filler, $d_{33 \mathrm{f}}$ the piezoelectric charge coefficient of the filler, $\mathrm{Y}_{33 \mathrm{f}}$ the elastic modulus of the ceramic inclusions, and $\mathrm{Y}_{\mathrm{p}}$ the elastic modulus of the polymer matrix.

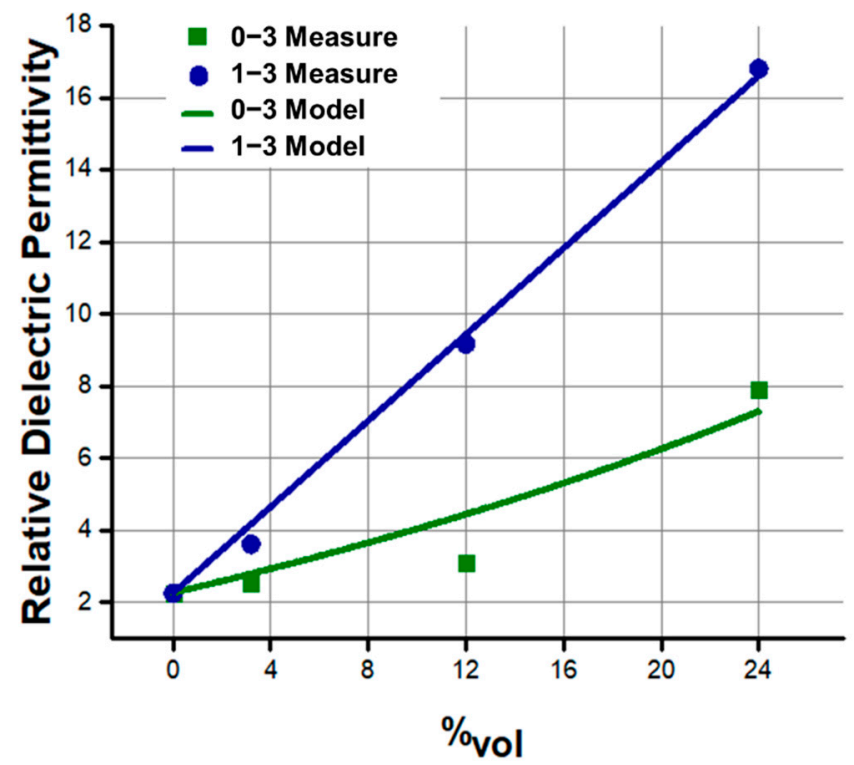

(a)

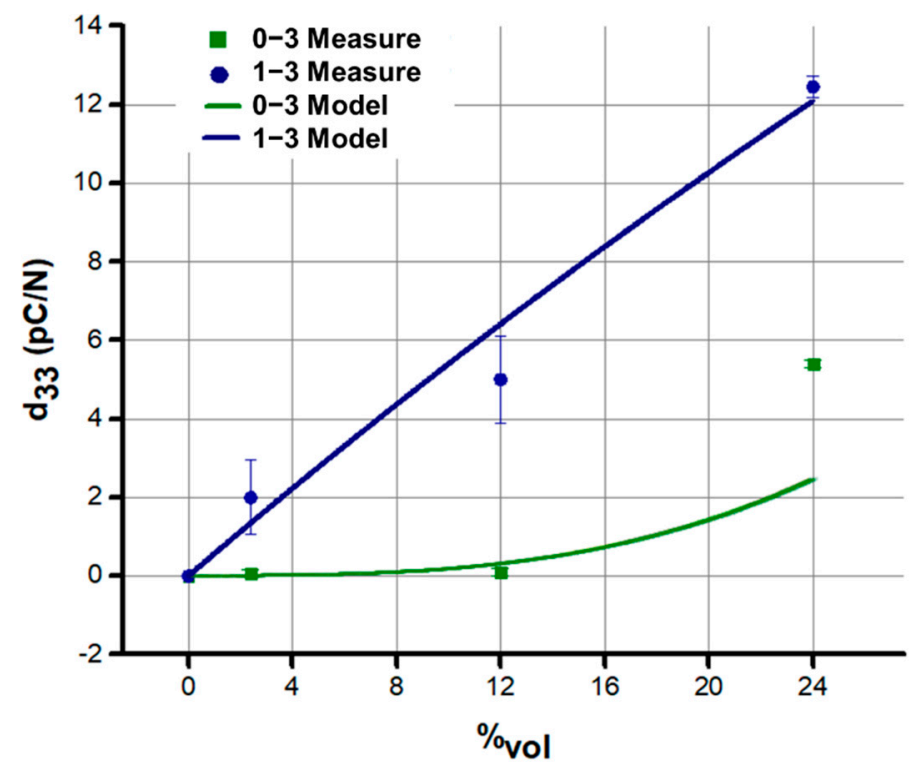

(b)

Figure 5. Cont. 


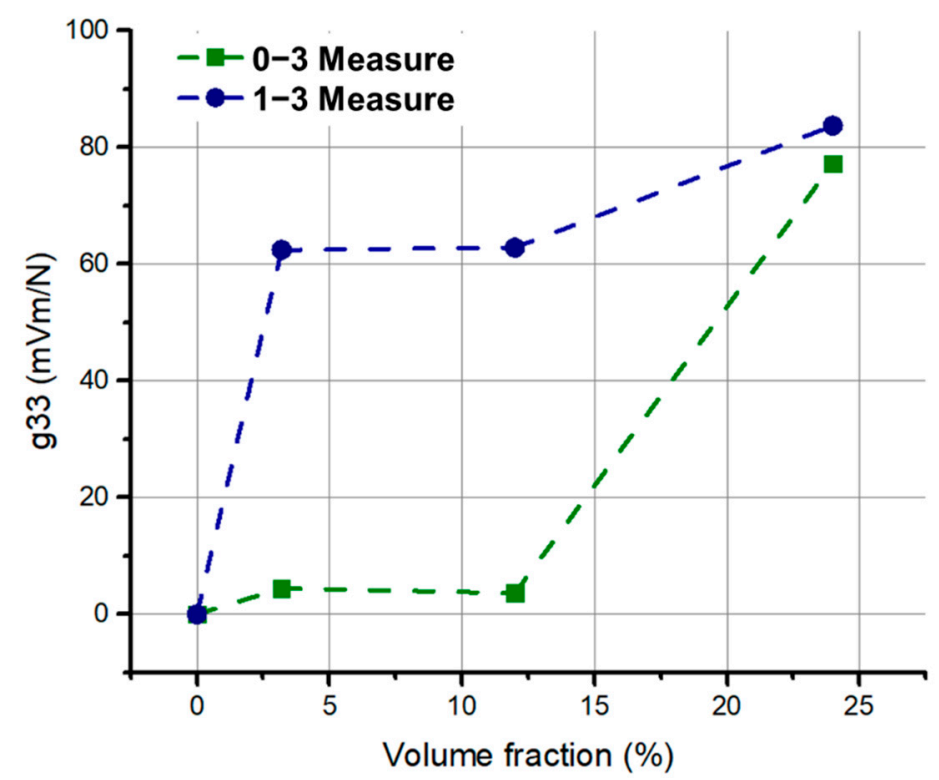

(c)

Figure 5. (a) Dielectric permittivity, (b) piezoelectric charge coefficient, and (c) piezoelectric voltage coefficient of 0-3 and 1-3 PZT/PDMS as a function of filler volume content. Comparison between experiment and analytical models was showed in $(\mathbf{a}, \mathbf{b})$.

As illustrated Figure 5b, empirical data effectively suit the theoretical trends reflecting high reliability of the proposed approach [8,33]. The piezoelectric voltage coefficient, $\mathrm{g}_{33}$, was then computed for all the prepared samples, according to Equation (5). This coefficient, indicating the electric field generated by a piezoelectric material per unit of mechanical stress, is important to assess a material's suitability for sensing and energy harvesting applications. All the structured samples lead to higher $\mathrm{g}_{33}$ with respect to the non-structured ones (Figure 5c).

$$
\mathrm{g}_{33}=\frac{\mathrm{d}_{33}}{\varepsilon_{0} \varepsilon_{\mathrm{r}}}
$$

\subsection{Thermal Study of Piezoelectric Activity and XRD Analysis}

Figure 6a shows the variation with temperature of $\mathrm{d}_{33}$ coefficient for $0-3$ and $1-3$ composites at $24 \%$ vol, normalized with respect to its value at $25{ }^{\circ} \mathrm{C}$. In $0-3$ composites, the piezoelectric coefficient starts to decrease at $50^{\circ} \mathrm{C}$, while in 1-3 composites it remains constant up to $100^{\circ} \mathrm{C}$, then gradually decreases. Interestingly, a small increase was observed for the $0-3$ sample after $150{ }^{\circ} \mathrm{C}$, which is possibly due to the measure error related to the instrument accuracy of around 5\%. Figure $6 \mathrm{~b}$ illustrates the data resulting from the XRD analysis performed at different temperatures $\left(25^{\circ} \mathrm{C}, 150{ }^{\circ} \mathrm{C}\right.$, and $\left.200^{\circ} \mathrm{C}\right)$. This study allowed to associate the results of the thermal analysis with the crystalline structure of the ceramic filler. At room temperature, PZT has a combination of two crystalline structures, tetragonal and rhombohedral, both ferroelectrics, and therefore with an asymmetry related to piezoelectric behavior, following alignment of the dipoles via poling procedure. The combination of these phases is called the morphotropic phase boundary (MPB). As shown in Figure $6 b$, the red arrows indicate the peaks of the tetragonal phase, while the blue arrow indicates the peak of the rhombohedral phase. This last peak decreases with increasing temperature and only tetragonal peaks remain at $200^{\circ} \mathrm{C}$. In $0-3$ connectivity, the rhombohedral phase peak disappears at lower temperature (i.e., $150{ }^{\circ} \mathrm{C}$ ) with respect to the 1-3 connectivity. This could justify the earlier decrease of piezoelectric properties. It is worth noting that there is no passage to cubic phase (i.e., corresponding to paraelectric behavior), which in fact only occurs above the Curie temperature $\left(\mathrm{T}_{\mathrm{C}} \approx 350{ }^{\circ} \mathrm{C}\right)$. In conclusion, the disappearance of the rhombohedral peak induces a slight decrease $(30 \%$ 
approximately) in the piezoelectric properties of the PZT. Nevertheless, the composite keeps a good piezoelectric response up to $200{ }^{\circ} \mathrm{C}$, which reveals to be suitable in a large application of sensing devices.

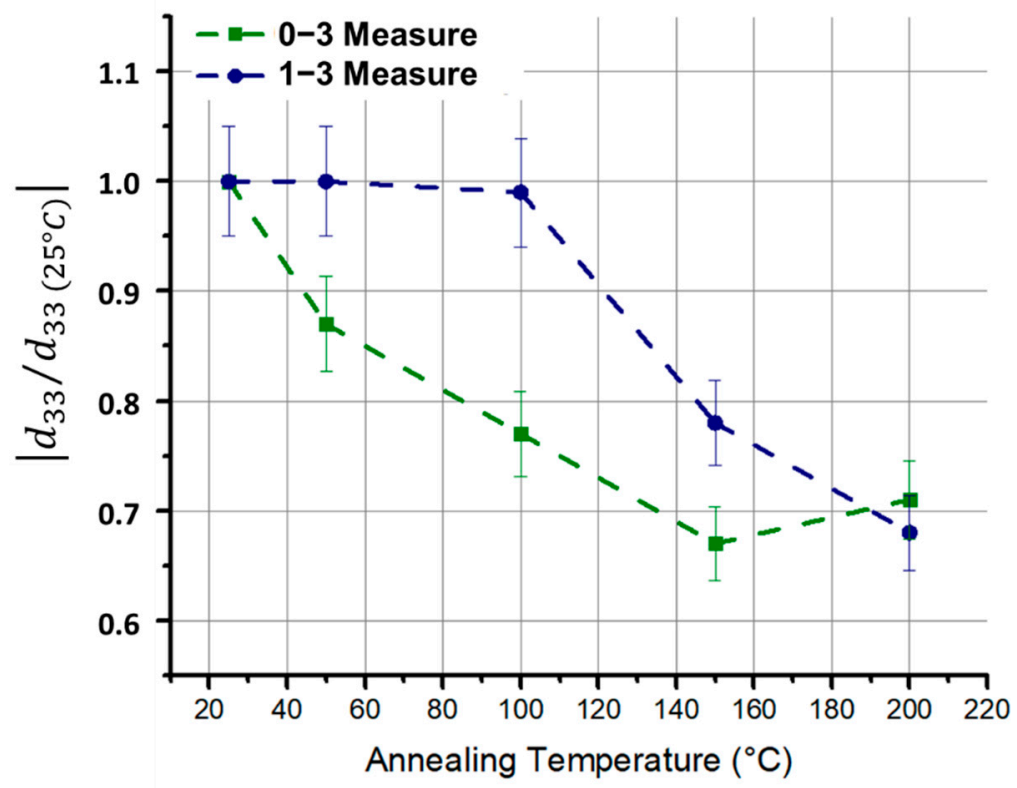

(a)

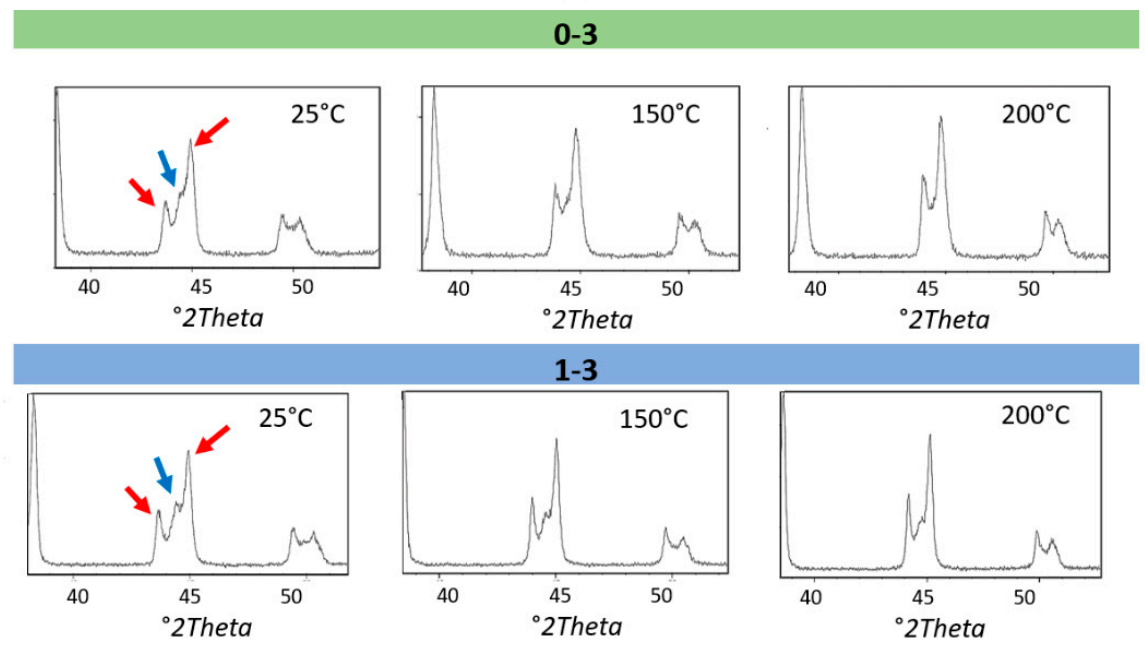

(b)

Figure 6. (a) Piezoelectric charge coefficient variation with annealing temperature of 0-3 and 1-3 PZT/ PDMS $24 \%$ vol. The value is normalized with respect to the value at $25^{\circ} \mathrm{C}$. (b) X-ray diffraction of 0-3 and 1-3 PZT/PDMS $24 \%$ vol at $25^{\circ} \mathrm{C}, 150^{\circ} \mathrm{C}$ and $200^{\circ} \mathrm{C}$. The red arrows indicate the tetragonal ferroelectric phase, while the blue one the rhombohedral phase.

\subsection{In-Situ Microscopic Observation}

Figure $7 \mathrm{a}, \mathrm{b}$ respectively display the frame of the $1 \%$ vol blend structuration subjected to a $2 \mathrm{~V} \mathrm{\mu m}^{-1}$ electric field of $2 \mathrm{~Hz}$ and $2 \mathrm{kHz}$, at different moments of the dielectrophoretic process $2 \mathrm{~Hz}$, forming coarser particle's chain-like structure, reveals to be more effective than $2 \mathrm{kHz}$, especially after $15 \mathrm{~min}$ of process. Different studies clearly indicated that dielectrophoresis is more effective under low frequency (i.e., around 1 to $10 \mathrm{~Hz}$ ). This behavior is probably due to slow polarization of the ceramic particles, which makes them unable to follow the electric field at a high dynamic (e.g., $100 \mathrm{~Hz}$ to $1 \mathrm{kHz}$ ). However, frequencies lower than $1 \mathrm{~Hz}$ were not considered as they would lead to inefficient structuration [25]. Indeed, at extremely low frequencies, the ionic species have time to redistribute 
themselves into charge layers near the electrodes, provoking the voltage drop and, therefore, inhibiting chain formation. Regarding the electric field amplitude, according to the literature, an excessively high input level would generate turbulence and consequently destroy the columns. Moreover, the value of electric field amplitude is limited by the dielectric breakdown of the polymer [25]. On the other hand, this value should be high enough to successfully align the particles in chain-like structure. Accordingly, $2 \mathrm{~V} \mathrm{\mu \textrm {m } ^ { - 1 }}$ seems to be the most suitable choice to achieve this compromise.

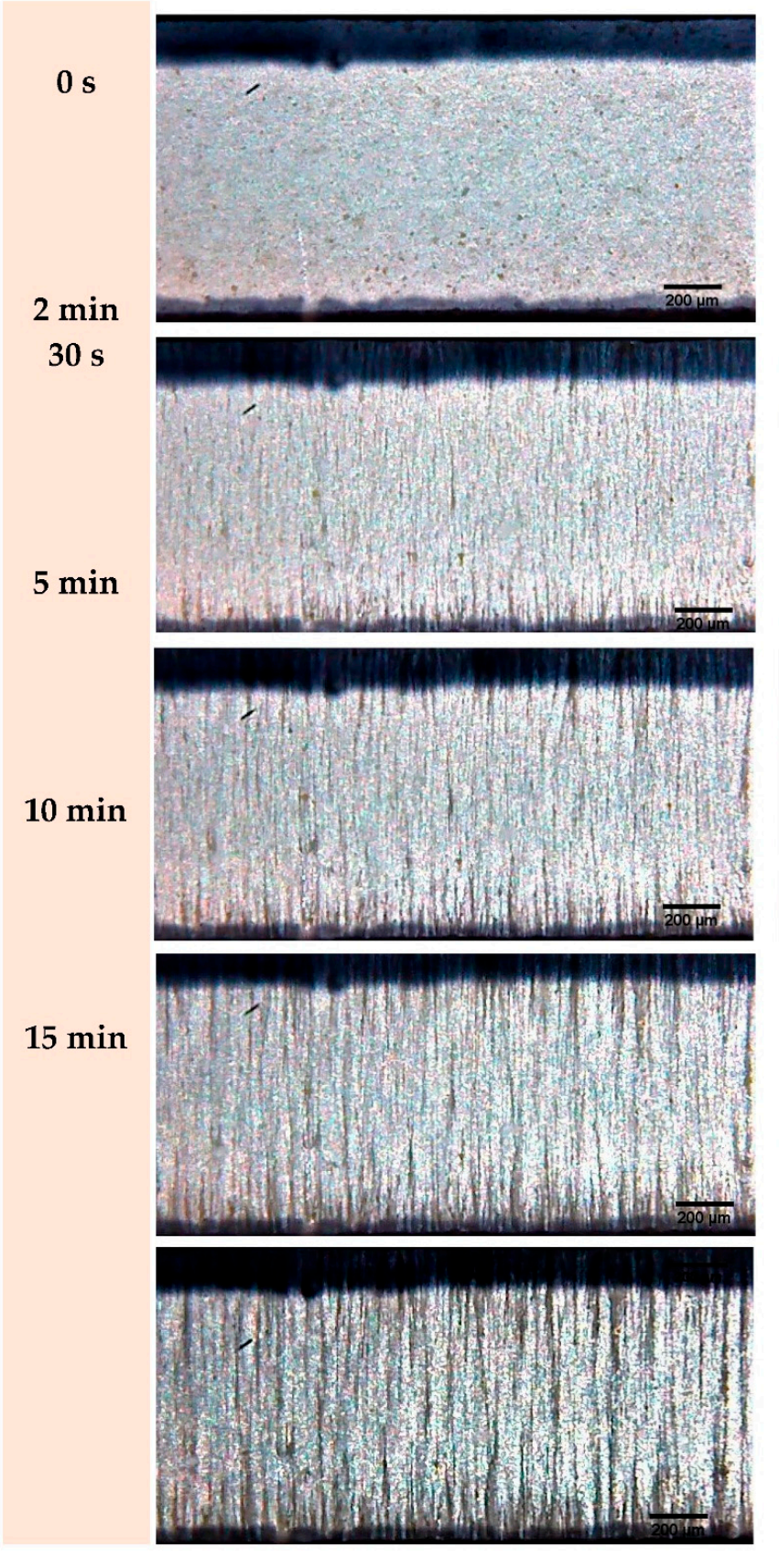

(a) $2 \mathrm{kV} \cdot \mathrm{mm}^{-1}, \quad 2 \mathrm{~Hz}$
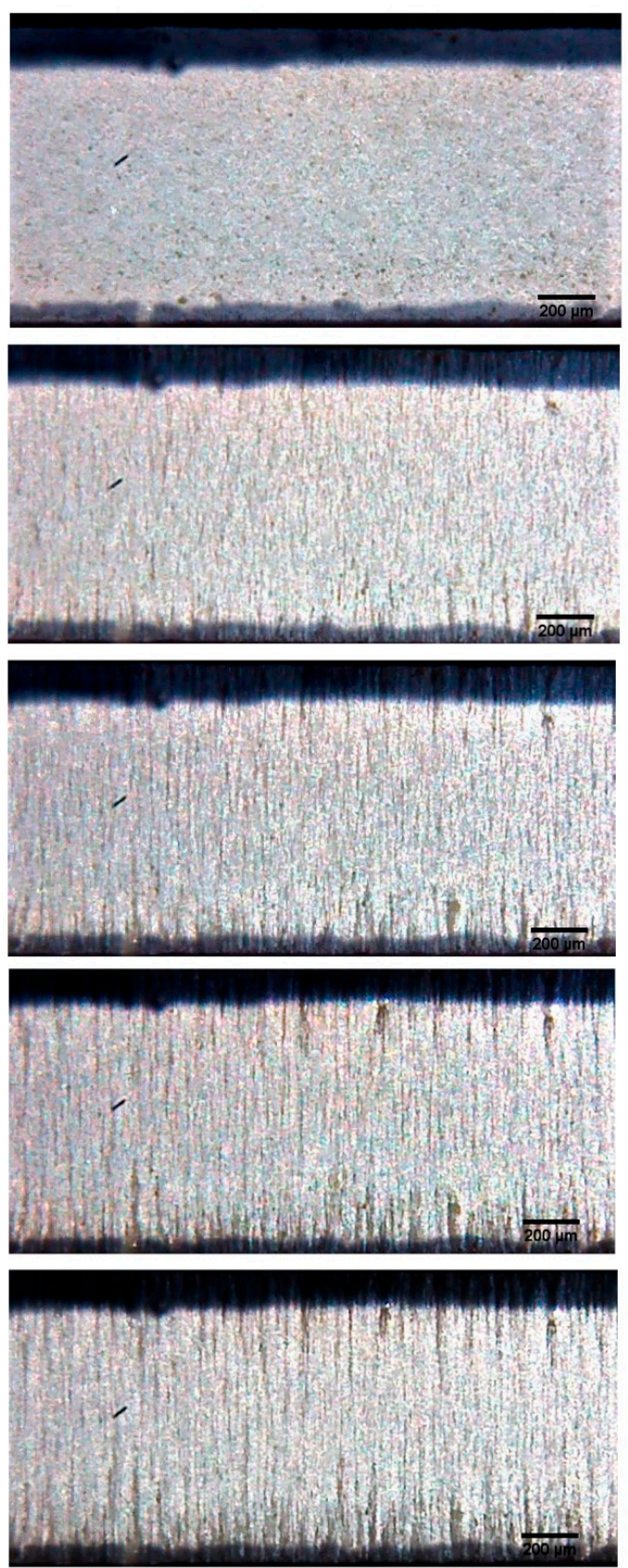

(b) $2 \mathrm{kV} . \mathrm{mm}^{-1}, \quad 2 \mathrm{kHz}$
$0 \mathrm{~s}$

$2 \mathrm{~min}$

$30 \mathrm{~s}$

5 min

$10 \mathrm{~min}$

$15 \mathrm{~min}$

Figure 7. Frame of in-situ microscopic observation during dielectrophoresis performed at $2 \mathrm{kV}$. $\mathrm{mm}^{-1}$ from 0 to $15 \mathrm{~min}$, with frequency of (a) $2 \mathrm{~Hz}$, and (b) $2 \mathrm{kHz}$. 
In order to validate this qualitative observation, a sample made with $24 \%$ vol with

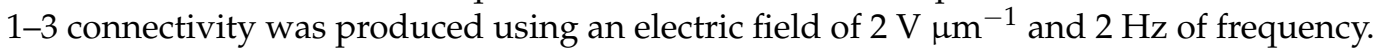
The $\mathrm{d}_{33}$ coefficient of the 1-3 sample (after being poled) was measured and compared to the same volume content sample but produced at $2 \mathrm{kHz}$, in order to confirm the best tuning parameter used in dielectrophoresis. The result reveals that the $d_{33}$ value of the sample carried out at $2 \mathrm{~Hz}$ reaches $16 \mathrm{pC} \mathrm{N}^{-1}$, corresponding to an improvement of around $30 \%$ with respect to the $2 \mathrm{kHz}$ counterpart. This observation is coherent to the microscopic analysis of Figure 4.

\subsection{Overview of the Piezoelectric Properties: Potential Application in Stretchable Electronics}

The proposed inorganic/organic piezoelectric composite has a great potential in the field of stretchable electronics and elastronic [47,48]. Figure 8a,b compares the piezoelectric sensitivity between our composite and other classical piezoelectric materials in terms of working temperature and mechanical strain, respectively. It is believed that our composite can undergo high strain and large temperature with respect to piezoelectric ceramics and ferroelectric polymer. Such properties could be required for many applications in different fields, for instance aerospace as elastomeric sensors for monitoring components [49,50]. As a matter of fact, sensing systems are usually made by hard materials and all their functionalities rely only on the electronic architecture and on the software embedded in the device chip. This approach has serious drawbacks since a rigid structure imposes severe limitations on the device application domains (mechanical deformation less than 1 or $2 \%$ ) [51]. In some cases, it is possible to overcome these limitations by augmenting the complexity either of the device physical structure or of the embedded software. This, however, results in an unwanted great increase in the final cost or in degraded performances. Thus, it is strategic to develop materials that facilitate disruptive or transformative changes while being fully compatible with standard electronics [52]. Hence, our proposed material does not act just as static structural component, but actively interacts with the environment. In other words, it can respond to external stimuli altering its physical properties in a way that can be exploited to improve the functionalities of a device. Figure 9 depicts a photograph of the stretched sample associated with its typical piezoelectric response.

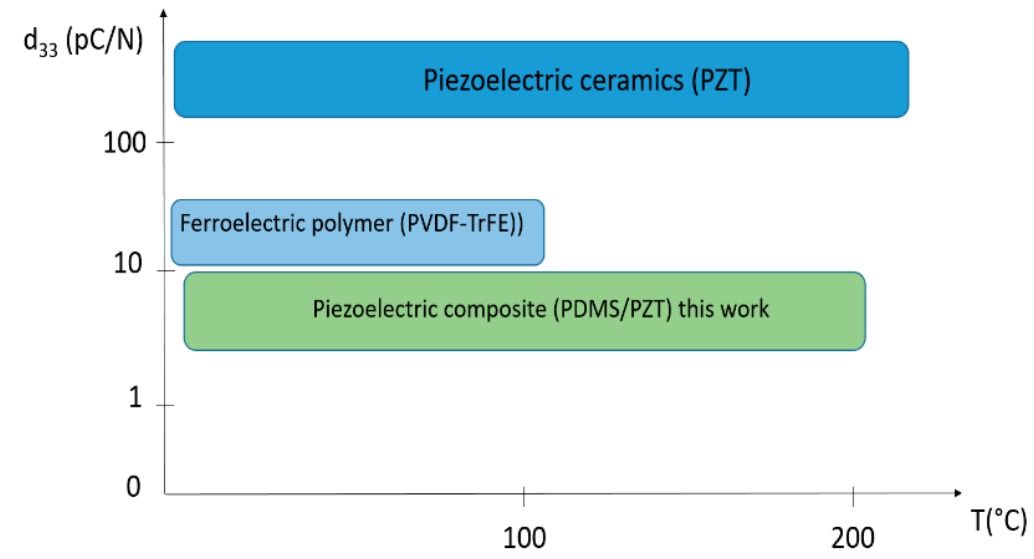

(a)

Figure 8. Cont. 


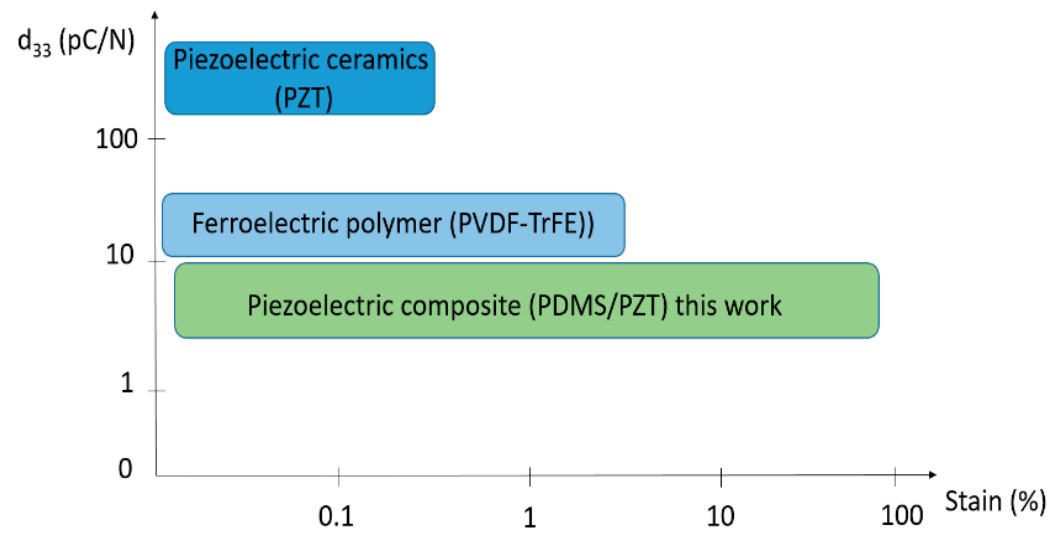

(b)

Figure 8. Overview of three typical piezoelectric materials (ceramic, polymer, composite) with their piezoelectric charge coefficient: (a) versus temperature, and (b) versus mechanical strain.

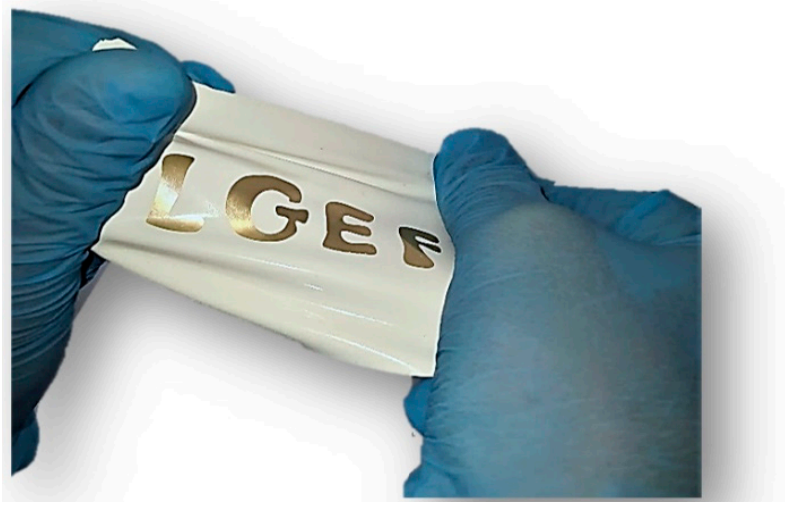

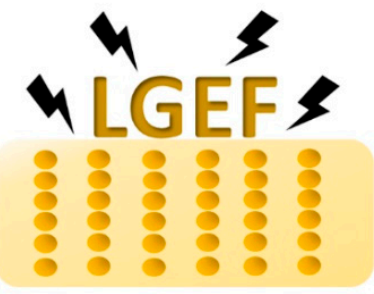

$16 \mathrm{pC} / \mathrm{N}$

Figure 9. Picture of stretched piezoelectric sensor developed in this study.

From a physical point of view, the proposed approach involves enhancement of the filler concentration along the alignment direction. In practice, all particles disposed in columns along the electric field lines, giving raise to enhanced electric polarizability of the dielectric material. It has been revealed that the 1-3 connectivity polarizes more in response to an applied electric field than the corresponding $0-3$, which explains why the permittivity is higher in the case of structured 1-3 sample. In practice, lower electric field is possible to fully polarize the aligned fillers within the matrix, while is not in a 0-3 composite. Actually, the matrix of this configuration substantially attract the electric field, inducing extremely poor amount of electric field in the filler [53,54]. Nonetheless, in 1-3 configuration, the enhancement of the electric field in the matrix gaps between the particles is high enough to reach full polarization of the particles. Consequently, under the same poling condition, the piezoelectric activity of the 1-3 composite significantly improved as opposed to the 0-3 counterpart.

\section{Conclusions}

In this work, we developed piezoelectric composites made of PZT microparticles, embedded in Silicone PDMS matrix, with two different internal connectivity, 0-3 and 1-3. SEM analysis provided a clear image of dielectrophoretic effect on the blend, confirming that such a process can successfully drive particles in column-like structure. Dielectric and the piezoelectric characterization of $0-3$ and 1-3 composites pointed out that the 13 connectivity leads to a 2 -fold improvement in the dielectric permittivity $\left(\varepsilon_{\mathrm{r}}\right)$, and more than 2.5 -fold in the piezoelectric charge coefficient $\left(\mathrm{d}_{33}\right)$, as opposed to the $0-3$ counterpart 
for $24 \%$ vol of filler concentration. Whatever the material connectivity (either $1-3$ or $0-3$ ), experimental trends of $\varepsilon_{\mathrm{r}}$ and $\mathrm{d}_{33}$ were in good agreement with theoretical models. To access the behavior of composites at high temperature, a study based on thermal stability coupled with XRD analysis were performed, allowing to verify the existence of ferroelectric crystalline structure until $200{ }^{\circ} \mathrm{C}$. Finally, an in-situ microscopy analysis led to the best parameters for alignment procedure. It was pointed out that a low frequency of $2 \mathrm{~Hz}$ gave raise to improved $d_{33}$ piezoelectric coefficient of $30 \%$ with respect to $2 \mathrm{kHz}$, which was conform with the microscopic observation.

In conclusion, the developed composite, whose piezoelectric sensitivity $\left(16 \mathrm{pC} \mathrm{N}^{-1}\right)$ is close to the one of conventional ferroelectric polymers $\left(20 \mathrm{pC} \mathrm{N}^{-1}\right)$, was successfully produced via dielectrophoresis. Besides its high piezoelectric activity, further advantages that make this material very attractive in several fields (structural health monitoring, energy harvesting, etc.) are cost effectiveness, easy processability, low poling electric field requirement, integrability in complex structures thanks to its flexibility, and ability to survive high temperature environments.

Author Contributions: G.D., P.-J.C. and M.-Q.L. designed the manuscript. G.D. and O.Z. elaborated the composites and performed the experimental tests. G.D. and O.Z. analyzed and plotted the data. J.-F.C. provided some help on experimental set-ups. This work was supervised by P.-J.C. and J.-F.C. All authors have read and agreed to the published version of the manuscript.

Funding: This research received no external funding.

Institutional Review Board Statement: Not applicable.

Informed Consent Statement: Not applicable.

Data Availability Statement: Not applicable.

Acknowledgments: All the authors acknowledge the financial support from the "Bonus Qualite Innovation" (BQI) from INSAVALOR. We also thank "Région Auvergne Rhone Alpes" for providing the thesis scholarship on health issue.

Conflicts of Interest: The authors declare no conflict of interest.

\section{References}

1. Uchino, K. Piezoelectric Composite Materials. Adv. Piezoelectric Mater. Sci. Technol. 2010. [CrossRef]

2. Akdogan, E.K.; Allahverdi, M.; Safari, A. Piezoelectric Composites for Sensor and Actuator Applications. IEEE Trans. Ultrason. Ferroelectr. Freq. Control 2005, 52, 746-775. [CrossRef]

3. Lee, H.J.; Zhang, S.; Bar-Cohen, Y.; Sherrit, S. High Temperature, High Power Piezoelectric Composite Transducers. Sensors 2014, 14, 14526-14552. [CrossRef]

4. Ramadan, K.S.; Sameoto, D.; Evoy, S. A Review of Piezoelectric Polymers as Functional Materials for Electromechanical Transducers. Smart Mater. Struct. 2014, 23. [CrossRef]

5. Su, Y.; Wu, Z.; Wu, X.; Long, Y.; Zhang, H.; Xie, G.; Du, X.; Tai, H.; Jiang, Y. Enhancing Responsivity of ZnO Nanowire Based Photodetectors by Piezo-Phototronic Effect. Sens. Actuators A Phys. 2016, 241, 169-175. [CrossRef]

6. Cottinet, P.-J.; Le, M.-Q.; Degraff, J.; Souders, C.; Liang, Z.; Wang, B.; Zhang, C. Strain Phenomenon in Carbon Nanotube Buckpaper Actuator: Experiments and Modeling. Sens. Actuators A Phys. 2013, 194, 252-258. [CrossRef]

7. Kim, T.; Cui, Z.; Chang, W.-Y.; Kim, H.; Zhu, Y.; Jiang, X. Flexible 1-3 Composite Ultrasound Transducers With Silver-NanowireBased Stretchable Electrodes. IEEE Trans. Ind. Electron. 2020, 67, 6955-6962. [CrossRef]

8. Khanbareh, H.; Topolov, V.Y.; Bowen, C.R. Piezo-Particulate Composites; Springer, Ed.; Springer Series in Materials Science; Springer International Publishing: Cham, Swizterland, 2019; Volume 283, ISBN 978-3-030-19203-7.

9. Carbone, C.; Benwadih, M.; D'Ambrogio, G.; LE, M.-Q.; Capsal, J.-F.; Cottinet, P.-J. Influence of Matrix and Surfactant on Piezoelectric and Dielectric Properties of Screen-Printed BaTiO3/PVDF Composites. Polymers 2021, 13, 2166. [CrossRef]

10. Jaffe, H. Piezoelectric Ceramics. J. Am. Ceram. Soc. 1958, 41, 494-498. [CrossRef]

11. Yu, K.; Hu, S.; Tan, J.; Yu, W. Dielectric and Piezoelectric Properties of (K0.475Na0.495Li0.03) NbO3-0.003ZrO2/PVDF 0-3 Composite Reinforced with Two Types of Nano-ZnO Particles. J. Mater. Sci. Mater. Electron. 2020, 31, 1367-1381. [CrossRef]

12. Carponcin, D.; Dantras, E.; Laffont, L.; Dandurand, J.; Aridon, G.; Levallois, F.; Cadiergues, L.; Lacabanne, C. Integrated Piezoelectric Function in a High Thermostable Thermoplastic PZT/PEEK Composite. J. Non-Cryst. Solids 2014, $388,32-36$. [CrossRef] 
13. Liu, Q.; Le, M.Q.; Richard, C.; Liang, R.; Cottinet, P.-J.; Capsal, J.-F. Enhanced Pseudo-Piezoelectric Dynamic Force Sensors Based on Inkjet-Printed Electrostrictive Terpolymer. Org. Electron. 2019, 67, 259-271. [CrossRef]

14. Della Schiava, N.; Le, M.-Q.; Galineau, J.; Domingues Dos Santos, F.; Cottinet, P.-J.; Capsal, J.-F. Influence of Plasticizers on the Electromechanical Behavior of a P(VDF-TrFE-CTFE) Terpolymer: Toward a High Performance of Electrostrictive Blends. J. Polym. Sci. Part B Polym. Phys. 2017, 55, 355-369. [CrossRef]

15. Capsal, J.-F.; Galineau, J.; Le, M.-Q.; Domingues Dos Santos, F.; Cottinet, P.-J. Enhanced Electrostriction Based on Plasticized Relaxor Ferroelectric P(VDF-TrFE-CFE/CTFE) Blends. J. Polym. Sci. Part B Polym. Phys. 2015, 53, 1368-1379. [CrossRef]

16. Ganet, F.; Le, M.-Q.; Capsal, J.F.; Gérard, J.F.; Pruvost, S.; Duchet, J.; Livi, S.; Lermusiaux, P.; Millon, A.; Cottinet, P.-J. Haptic Feedback Using an All-Organic Electroactive Polymer Composite. Sens. Actuators B Chem. 2015, 220, 1120-1130. [CrossRef]

17. Della Schiava, N.; Thetpraphi, K.; Le, M.-Q.; Lermusiaux, P.; Millon, A.; Capsal, J.-F.; Cottinet, P.-J. Enhanced Figures of Merit for a High-Performing Actuator in Electrostrictive Materials. Polymers 2018, 10, 263. [CrossRef] [PubMed]

18. Sa-Gong, G.; Safari, A.; Jang, S.J.; Newnham, R.E. Poling Flexible Piezoelectric Composites. Ferroelectr. Lett. Sect. 1986, 5, 131-142. [CrossRef]

19. Dai, X.; Wen, Y.; Li, P.; Yang, J.; Li, M. Energy Harvesting from Mechanical Vibrations Using Multiple Magnetostrictive/Piezoelectric Composite Transducers. Sens. Actuators A Phys. 2011, 166, 94-101. [CrossRef]

20. Konka, H.P.; Wahab, M.A.; Lian, K. Piezoelectric Fiber Composite Transducers for Health Monitoring in Composite Structures. Sens. Actuators A Phys. 2013, 194, 84-94. [CrossRef]

21. Le, M.Q.; Ganet, F.; Audigier, D.; Capsal, J.-F.; Cottinet, P.-J. Printing of Microstructure Strain Sensor for Structural Health Monitoring. Appl. Phys. A 2017, 123, 354. [CrossRef]

22. Kim, T.; Kim, J.; Jiang, X. Transit Time Difference Flowmeter for Intravenous Flow Rate Measurement Using 1-3 Piezoelectric Composite Transducers. IEEE Sens. J. 2017, 17, 5741-5748. [CrossRef]

23. Sharma, T.; Aroom, K.; Naik, S.; Gill, B.; Zhang, J.X.J. Flexible Thin-Film PVDF-TrFE Based Pressure Sensor for Smart Catheter Applications. Ann. Biomed. Eng. 2013, 41, 744-751. [CrossRef]

24. Shung, K.K.; Cannata, J.M.; Zhou, Q.F. Piezoelectric Materials for High Frequency Medical Imaging Applications: A Review. J. Electroceramics 2007, 19, 141-147. [CrossRef]

25. D'Ambrogio, G.; Zahhaf, O.; Bordet, M.; Le, M.Q.; Della Schiava, N.; Liang, R.; Cottinet, P.-J.; Capsal, J.-F. Structuring BaTiO 3 /PDMS Nanocomposite via Dielectrophoresis for Fractional Flow Reserve Measurement. Adv. Eng. Mater. 2021. [CrossRef]

26. Su, Y.; Chen, C.; Pan, H.; Yang, Y.; Chen, G.; Zhao, X.; Li, W.; Gong, Q.; Xie, G.; Zhou, Y.; et al. Muscle Fibers Inspired High-Performance Piezoelectric Textiles for Wearable Physiological Monitoring. Adv. Funct. Mater. 2021, 31, 2010962. [CrossRef]

27. Su, Y.; Wang, J.; Wang, B.; Yang, T.; Yang, B.; Xie, G.; Zhou, Y.; Zhang, S.; Tai, H.; Cai, Z.; et al. Alveolus-Inspired Active Membrane Sensors for Self-Powered Wearable Chemical Sensing and Breath Analysis. ACS Nano 2020, 14, 6067-6075. [CrossRef]

28. Su, Y.; Yang, T.; Zhao, X.; Cai, Z.; Chen, G.; Yao, M.; Chen, K.; Bick, M.; Wang, J.; Li, S.; et al. A Wireless Energy Transmission Enabled Wearable Active Acetone Biosensor for Non-Invasive Prediabetes Diagnosis. Nano Energy 2020, 74, 104941. [CrossRef]

29. Zhang, X.; Villafuerte, J.; Consonni, V.; Capsal, J.-F.; Cottinet, P.-J.; Petit, L.; Le, M.-Q. Characterizing and Optimizing Piezoelectric Response of ZnO Nanowire/PMMA Composite-Based Sensor. Nanomaterials 2021, 11, 1712. [CrossRef]

30. Kar-Gupta, R.; Venkatesh, T.A. Electromechanical Response of Piezoelectric Composites: Effects of Geometric Connectivity and Grain Size. Acta Mater. 2008, 56, 3810-3823. [CrossRef]

31. Skinner, D.P.; Newnham, R.E.; Cross, L.E. Connectrivity and Piezoelectric-Pyroelectric Composites. Mater. Res. Bull. 1978, 13, 599-607. [CrossRef]

32. Khanbareh, H.; van der Zwaag, S.; Groen, W.A. Effect of Dielectrophoretic Structuring on Piezoelectric and Pyroelectric Properties of Lead Titanate-Epoxy Composites. Smart Mater. Struct. 2014, 23, 105030. [CrossRef]

33. Van Den Ende, D.A.; Bory, B.F.; Groen, W.A.; Van Der Zwaag, S. Improving the D33 and G33 Properties of 0-3 Piezoelectric Composites by Dielectrophoresis. J. Appl. Phys. 2010, 107, 024107. [CrossRef]

34. Zhang, X.; Le, M.-Q.; Zahhaf, O.; Capsal, J.-F.; Cottinet, P.-J.; Petit, L. Enhancing Dielectric and Piezoelectric Properties of Micro-ZnO/PDMS Composite-Based Dielectrophoresis. Mater. Des. 2020, 192, 108783. [CrossRef]

35. Sharma, T.; Je, S.-S.; Gill, B.; Zhang, J.X.J. Patterning Piezoelectric Thin Film PVDF-TrFE Based Pressure Sensor for Catheter Application. Sens. Actuators A Phys. 2012, 177, 87-92. [CrossRef]

36. Babu, I. Piezoelectric Composites: Design, Fabrication and Performance Analysis; Eindhoven, T.U., Ed.; Technische Universiteit Eindhoven: Eindhoven, The Netherlands, 2013; ISBN 9789038634838.

37. Park, C.; Robertson, R.E. Aligned Microstructure of Some Particulate Polymer Composites Obtained with an Electric Field. J. Mater. Sci. 1998, 33, 3541-3553. [CrossRef]

38. Bowen, C.P.; Shrout, T.R.; Newnham, R.E.; Randall, C.A. Tunable Electric Field Processing of Composite Materials. J. Intell. Mater. Syst. Struct. 1995, 6, 159-168. [CrossRef]

39. Grinberg, D.; Siddique, S.; Le, M.; Liang, R.; Capsal, J.; Cottinet, P. 4D Printing Based Piezoelectric Composite for Medical Applications. J. Polym. Sci. Part B Polym. Phys. 2019, 57, 109-115. [CrossRef]

40. Xiang, Z.; Nguyen, V.; Ducharne, B.; Della Schiava, N.; Capsal, J.; Cottinet, P.; Le, M. 3D Printing of Flexible Composites via Magnetophoresis: Toward Medical Application Based on Low-Frequency Induction Heating Effect. Macromol. Mater. Eng. 2021, 2100211. [CrossRef] 
41. D'Ambrogio, G.; Zahhaf, O.; Hebrard, Y.; Le, M.Q.; Cottinet, P.-J.; Capsal, J.-F. Micro-Structuration of Piezoelectric Composites Using Dielectrophoresis: Toward Application in Condition Monitoring of Bearings. Adv. Eng. Mater. 2021, 23, 2000773. [CrossRef]

42. Bowen, C.P.; Newnham, R.E.; Randall, C.A. Dielectric Properties of Dielectrophoretically Assembled Particulate-Polymer Composites. J. Mater. Res. 1998, 13, 205-210. [CrossRef]

43. Khanbareh, H.; van der Zwaag, S.; Groen, W. In-Situ Poling and Structurization of Piezoelectric Particulate Composites. J. Intell. Mater. Syst. Struct. 2017, 28, 2467-2472. [CrossRef]

44. Capsal, J.F.; Dantras, E.; Laffont, L.; Dandurand, J.; Lacabanne, C. Nanotexture Influence of BaTiO3 Particles on Piezoelectric Behaviour of PA 11/BaTiO3 Nanocomposites. J. Non-Cryst. Solids 2010, 356, 629-634. [CrossRef]

45. Zhang, X.; Le, M.-Q.; Nguyen, V.-C.; Mogniotte, J.-F.; Capsal, J.-F.; Grinberg, D.; Cottinet, P.-J.; Petit, L. Characterization of Micro-ZnO/PDMS Composite Structured via Dielectrophoresis-Toward Medical Application. Mater. Des. 2021, 208 , 109912. [CrossRef]

46. Van den Ende, D.A. Structured Piezoelectric Composites; 2012; ISBN 9789461913463.

47. Tee, B.C.K.; Ouyang, J. Soft Electronically Functional Polymeric Composite Materials for a Flexible and Stretchable Digital Future. Adv. Mater. 2018, 30, 1802560. [CrossRef] [PubMed]

48. Kim, D.C.; Shim, H.J.; Lee, W.; Koo, J.H.; Kim, D. Material-Based Approaches for the Fabrication of Stretchable Electronics. Adv. Mater. 2020, 32, 1902743. [CrossRef] [PubMed]

49. Deligianni, A.; Hale, J.M.; Kotsikos, G. Development of Piezoelectric Thick-Film Sensors to Be Embedded into Adhesively Bonded Joints. Plast. Rubber Compos. 2016, 45, 173-180. [CrossRef]

50. Rao, J.; Chen, Z.; Zhao, D.; Yin, Y.; Wang, X.; Yi, F. Recent Progress in Self-Powered Skin Sensors. Sensors 2019, 19, 2763. [CrossRef]

51. Zhao, Y.; Huang, X. Mechanisms and Materials of Flexible and Stretchable Skin Sensors. Micromachines 2017, 8, 69. [CrossRef]

52. Liu, S.; Shah, D.S.; Kramer-Bottiglio, R. Highly Stretchable Multilayer Electronic Circuits Using Biphasic Gallium-Indium. Nat. Mater. 2021, 20, 851-858. [CrossRef]

53. Pedroli, F.; Flocchini, A.; Marrani, A.; Le, M.-Q.; Sanseau, O.; Cottinet, P.-J.; Capsal, J.-F. Boosted Energy-Storage Efficiency by Controlling Conduction Loss of Multilayered Polymeric Capacitors. Mater. Des. 2020, 192, 108712. [CrossRef]

54. Zhang, X.; Le, M.-Q.; Mogniotte, J.; Capsal, J.-F.; Cottinet, P.-J.; Petit, L. Effect of Dielectrophoretic Structuring on Dielectric and Piezoelectric Behaviors of ZnO/PDMS Microcomposite. In Proceedings of the Electroactive Polymer Actuators and Devices (EAPAD) XXIII, 22 March 2021; SPIE. Madden, J.D., Anderson, I.A., Shea, H.R., Eds.; p. 41. 